\title{
Analisis Perbandingan Stabilitas Retaining Wall Soldier Piles dengan Reinforced Earth Wall
}

\author{
Arintha Indah Dwi Syafiarti ${ }^{1}$, Faisal Hamdan ${ }^{2}$, Fahmi Firdaus Alrizal ${ }^{3}$ \\ ${ }_{1,3}$ Jurusan Teknik Sipil, Fakultas Teknik Sipil dan Perencanaan, Institut Teknologi Adhi Tama Surabaya \\ ${ }^{2}$ Departemen Teknik Sipil, Fakultas Teknik Sipil, Lingkungan, dan Kebumian, Institut Teknologi Sepuluh \\ Nopember \\ Email: ${ }^{1}$ arintha@itats.ac.id, ${ }^{2}$ faisalhamdan.id@gmail.com, ${ }^{3}$ fahmi.alrizal@itats.ac.id
}

\begin{abstract}
Serpong-Balaraja Toll Road is an infrastructure project expected to solve the traffic density problem in southern Tangerang. In the Serpong-Balaraja Toll project, a retaining wall designed and located at STA $2+200-S T A 2+400$, to hold the backfill with on/off ramp road loading. This study carried out to compare retaining wall design using the soldier piles method and geogrid reinforced earth wall. The modeling of the internal stability on each method of retaining wall using PLAXIS. And the external stability is calculated based on lateral earth pressure. The result shows soil retaining walls using soldier piles has higher internal stability than the reinforced earth wall method.
\end{abstract}

Keywords: reinforced earth wall, soldier piles, stability

\begin{abstract}
Abstrak
Tol Serpong Balaraja adalah proyek infrastuktur yang diharapkan menjadi solusi pemecahan masalah kepadatan lalu lintas di Tangerang Selatan. Pada proyek Tol Serpong Balaraja terdapat pekerjaan dinding penahan tanah pada STA $2+200-$ STA $2+400$ untuk menahan timbunan yang menerima beban jalan on/off ramp. Tujuan dari studi ini adalah untuk mengetahui perbandingan antara perencanaan dinding penahan tanah menggunakan metode soldier piles dan reinforced earth wall dengan perkuatan geogrid. Permodelan stabilitas internal dinding penahan tanah pada setiap metode dilakukan menggunakan PLAXIS. Dan stabilitas eksternal dihitung berdasarkan tegangan tanah horizontal. Hasil analisis menunjukkan bahwa dinding penahan tanah yang menggunakan soldier piles, menunjukkan stabilitas internal yang lebih besar daripada metode reinforced earth wall.
\end{abstract}

Kata kunci: reinforced earth wall, soldier piles, stabilitas

\section{Pendahuluan}

Jalan Tol Serpong - Balaraja merupakan jaringan jalan yang menghubungkan daerah Serpong sampai Balaraja di wilayah Tangerang Selatan, Provinsi Banten. Proyek ini merupakan salah satu proyek infrastuktur negara yang menjadi solusi dari masalah kepadatan lalu lintas di Tangerang Selatan. Proyek Tol Serpong Balaraja terdiri dari beberapa jenis pekerjaan, dimana salah satunya terdapat pekerjaan dinding penahan tanah di lokasi STA 2+200 - STA 2+400 yang ditunjukkan pada Gambar 1. Proyek Tol Serpong Balaraja STA 2+200 - 2+400 dibangun di atas galian tanah dan pada jalan on/off ramp berada diatas timbunan dengan level tanah dasar yang bervariasi, sehingga area tersebut dikelilingi oleh dinding penahan tanah untuk menahan lereng akibat tanah timbunan tersebut.

Dalam perencanaannya, dinding penahan tanah menggunakan soldier piles untuk menahan timbunan dengan tinggi lebih dari $4 \mathrm{~m}$. Soldier Piles dalam pengaplikasiannya dilaksanakan dengan pengeboran borepiles berdiameter $80 \mathrm{~cm}$ dan kedalaman $19 \mathrm{~m}$. Setelah pengeboran dan pengecoran selesai maka dilanjutkan pemasangan capping beam berdimensi $1 \times 1.6 \mathrm{~m}$ diatas soldier piles. Alternatif lain dari soldier piles tersebut adalah penggunaan metode reinforced earth wall sebagai dinding penahan tanah yang disusun dengan modular block. Setelah itu, setiap layer penimbunan diberikan lapisan geogrid untuk menahan tarik dari tegangan geser dalam tanah. Pada studi ini, dilakukan perbandingan 
terhadap stabilitas internal dinding penahan tanah tipe soldier piles dan reinforced earth wall yang dipasang pada lokasi yang ditunjukkan pada Gambar 1 dengan analisis yang dilakukan berdasarkan hasil permodelan menggunakan PLAXIS. Perhitungan stabilitas eksternal dilakukan berdasarkan tegangan horizontal yamg terjadi dalam sistem dinding penahan tanah. Hasil analisis dapat dijadikan acuan dalam pemilihan alternatif metode untuk pekerjaan dinding penahan tanah.

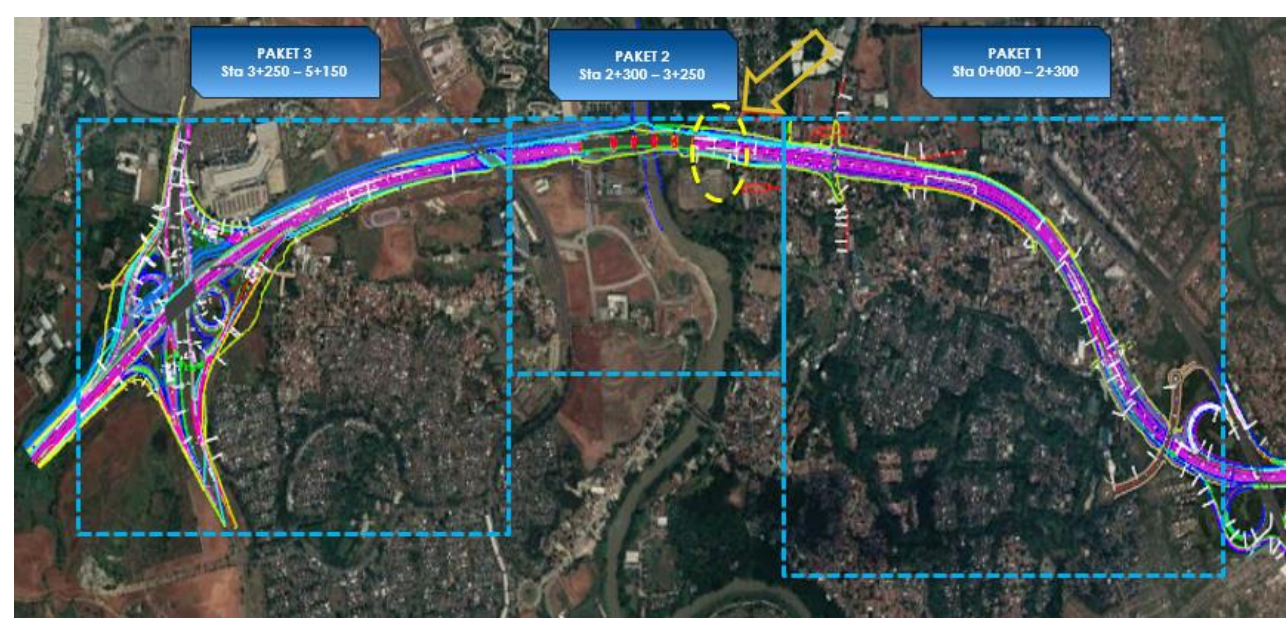

Gambar 1. Lokasi Pekerjaan Dinding Penahan Tanah

\section{Metode}

Berdasarkan hasil penyelidikan tanah pada lokasi STA $2+300$, diperoleh data tanah dasar untuk perencanaan teknis dinding penahan tanah yang ditunjukkan pada Gambar 2. Selain itu, beberapa referensi lain terkait pekerjaan dinding penahan tanah dari buku maupun jurnal diolah sebagai dasar dalam studi ini.

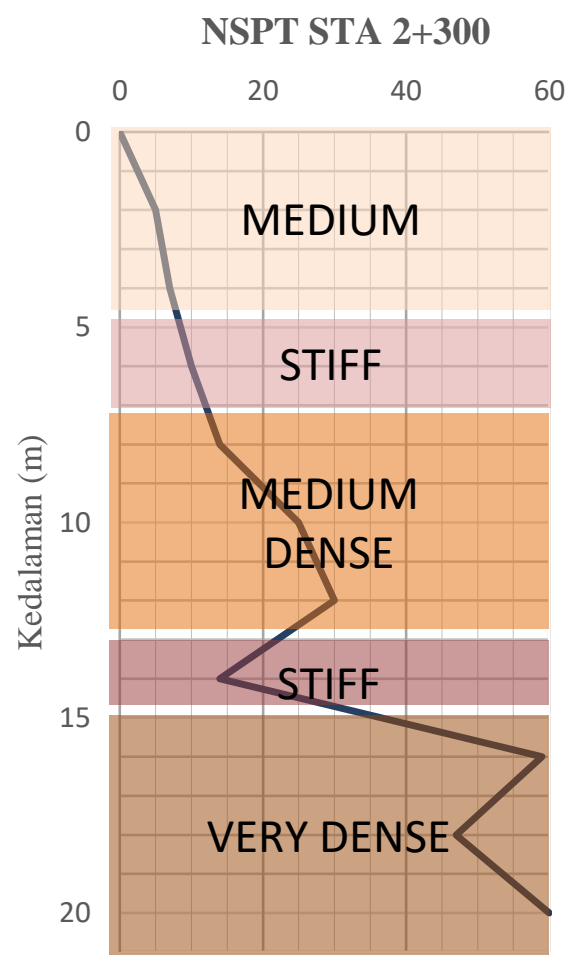

Gambar 2. Data NSPT pada STA $2+300$ 
Desain dinding penahan tanah direncanakan untuk menahan tanah timbunan dengan tinggi bervariasi, yaitu pada STA 2+200 setinggi 6,2 m dan STA 2+300 setinggi 4,5 m. Beban di atas tanah timbunan adalah beban lalu lintas, dimana jalan Tol Serpong Balaraja dikategorikan sebagai jalan kolektor primer dengan besar $\mathrm{q}=15 \mathrm{kN} / \mathrm{m}^{2}$. Data soldier piles meliputi diameter $80 \mathrm{~cm}$, panjang tiang $19 \mathrm{~m}$, dan interval antar soldier piles yaitu $1 \mathrm{~m}$, seperti yang ditunjukkan pada Gambar 3.

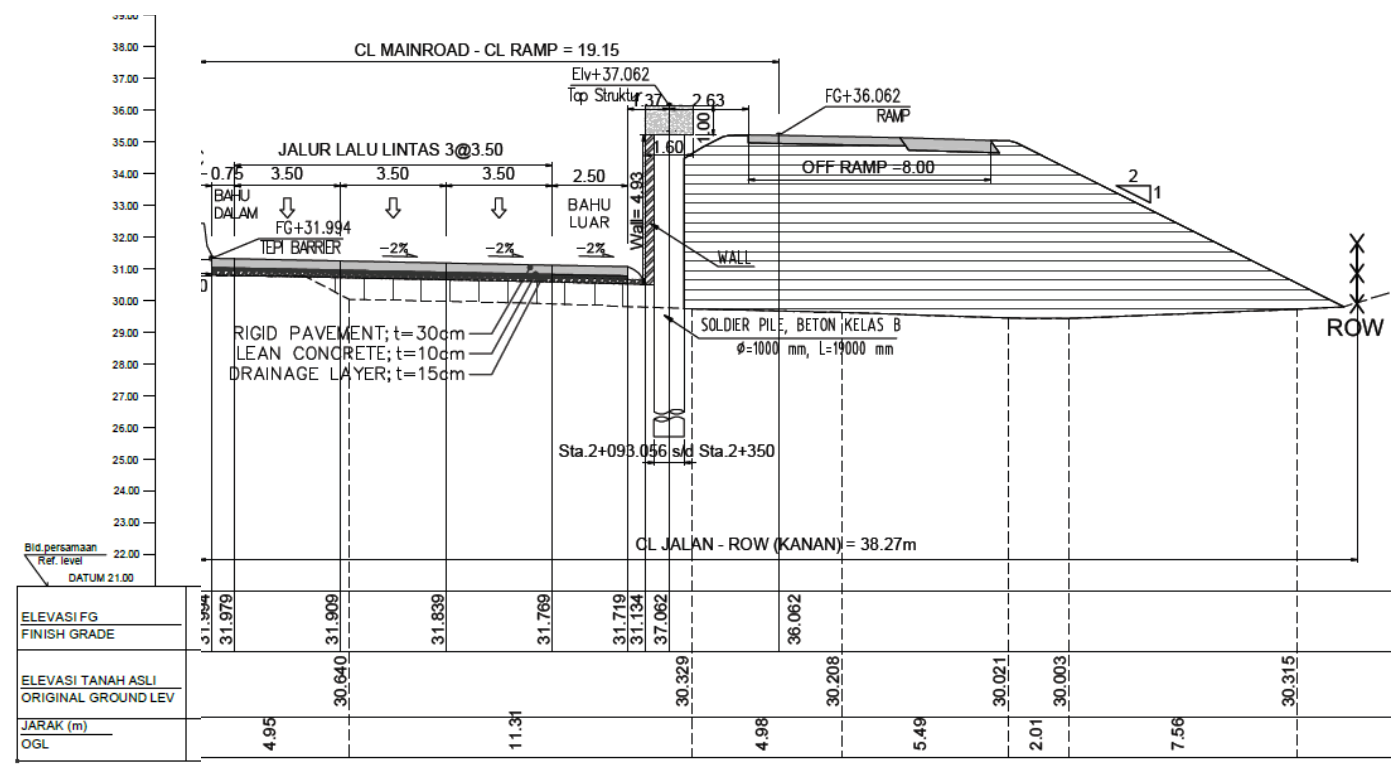

Gambar 3. Potongan Melintang Soldier Piles di STA $2+300$

Permodelan dalam software PLAXIS, menggunakan data NSPT yang telah diolah sebagai input karakteristik tanah tanah pada masing-masing lapisan tanah asli dengan angka Poisson ratio untuk semua lapisan tanah tersebut sebesar $v=0,3$. Rencana jaring atau mesh element pada model geometri ditampilkan pada Gambar 4. Berdasarkan data tanah boring log Sta $2+300$ muka air tanah berada di kedalaman $5 \mathrm{~m}$ dari permukaan tanah eksisting. Step kalkulasi dalam permodelan PLAXIS untuk dinding penahan tanah dengan soldier piles, dimulai dari pengeboran, galian tanah, pembebanan, pembebanan tanpa gempa, dan pembebanan gempa. Perhitungan beban gempa berdasarkan pada lokasi Proyek Tol Serpong - Balaraja yang berada di wilayah Tangerang Selatan termasuk dalam zona gempa 4, serta frekuensi yang digunakan sebagai input pembebanan dalam PLAXIS adalah data frekuensi gempa yang pernah terjadi. Faktor keamanan lereng dengan pembebanan gempa menurun dibandingkan tanpa menggunakan beban gempa [1].

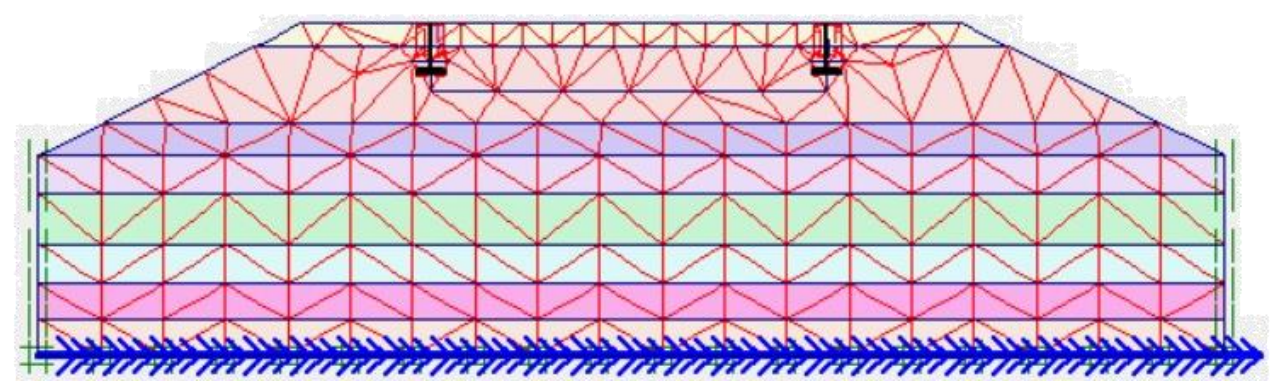

Gambar 4. Tampak Generate Mesh pada PLAXIS

Untuk metode reinforced earth wall, studi ini menganalisis hasil data sekunder yang menggunakan program PLAXIS untuk mendapat angka keamanan dinding penahan tanah pada kondisi tanpa gempa dan dengan gempa yang ditunjukkan pada Tabel 1. Reinforced earth wall setinggi $12 \mathrm{~m}$ 
dan menggunakan geogrid dengan panjang bervariasi antara $6-10 \mathrm{~m}$, sebagai separasi lapisan drainase dengan tanah timbunan pilihan, supaya butiran halus tidak masuk ke dalam lapisan drainase.

Tabel 1. Angka keamanan Reinforced Earth Wall tinggi $12 \mathrm{~m}$.

\begin{tabular}{llc}
\hline No. & Keterangan & Angka Keamanan \\
\hline 1. & Kondisi tanpa gempa & 1.85 \\
2. & Kondisi dengan gempa & 1.36 \\
\hline
\end{tabular}

Selain menganalisis angka keamanan dinding penahan tanah menggunakan soldier piles maupun reinforced earth wall, dalam studi ini dilakukan analisis terhadap stabilitas eksternal yang meliputi angka keamanan terhadap geser (sliding) dan guling (overturning) pada masing-masing tipe dinding penahan tanah dalam studi ini. Kontrol terhadap stabilitas geser dihitung berdasarkan rumus (1) untuk menghitung stabilitas eksternal dinding penahan tanah menggunakan soldier piles [2][3].

$$
S F_{\text {geser }}=\frac{\sum R h}{\sum F h}
$$

Kontrol terhadap stabilitas geser dihitung berdasarkan rumus (2) untuk menghitung stabilitas eksternal dengan reinforced earth wall perkuatan geogrid [4].

$$
S F_{\text {geser }}=\frac{W \cdot \beta \cdot \operatorname{tg} \varphi+A \cdot \beta \cdot c}{P a}
$$

Angka keamanan stabilitas eksternal terhadap guling untuk dinding penahan tanah menggunakan soldier piles maupun reinforced earth wall perkuatan geogrid dihitung berdasarkan rumus (3) [2][4].

$$
S F_{\text {guling }}=\frac{\sum M p}{\sum M a}
$$

Dimana : $\mathrm{Rh}:$ Tahanan dinding penahan tanah terhadap penggeseran; $\mathrm{Ph}=$ jumlah tekanan horizontal; W : Berat konstruksi; $\beta: 0,67-0,75$ (tipe geogrid $=0,75$ ); $\phi:$ Sudut gesek dalam tanah di bawah konstruksi; c : Kohesi tanah di bawah konstruksi; Pa : Gaya aktif tanah di belakang konstruksi; Mp : Momen perlawanan untuk menahan agar konstruksi tidak terguling; Ma : Momen yang menggulingkan; SF : Angka keamanan.

Angka Keamanan (SF) dibagi 3 kelompok rentang apabila ditinjau dari intensitas kelongsorannya seperti terlihat pada Tabel 2 [5].

Tabel 2. Hubungan Nilai Faktor Keamanan Lereng dan Intensitas Longsor.

\begin{tabular}{ll}
\hline Angka Keamanan $($ SF) & \multicolumn{1}{c}{ Intensitas Longsor } \\
\hline$<1,07$ & Longsor biasa/sering terjadi (lereng labil) \\
$1,07<\mathrm{SF}<1,25$ & Longsor pernah terjadi (lereng kritis) \\
$>1,25$ & Longsor jarang terjadi (lereng relatif stabil) \\
\hline
\end{tabular}

\section{Hasil dan Pembahasan}

Pada Gambar 5 menunjukkan deformasi pada mesh element untuk dinding penahan tanah dengan soldier piles dalam kondisi tanpa gempa. Deformasi terbesar terlihat pada lapisan tanah timbunan dibawah perkerasan jalan yang berada di belakang dinding penahan tanah. Tabel 3 menunjukkan angka keamanan dinding penahan tanah dengan soldier piles sepanjang $19 \mathrm{~m}$. Hasil tersebut memenuhi syarat angka keamanan sebesar $\mathrm{SF}>1,25$. 


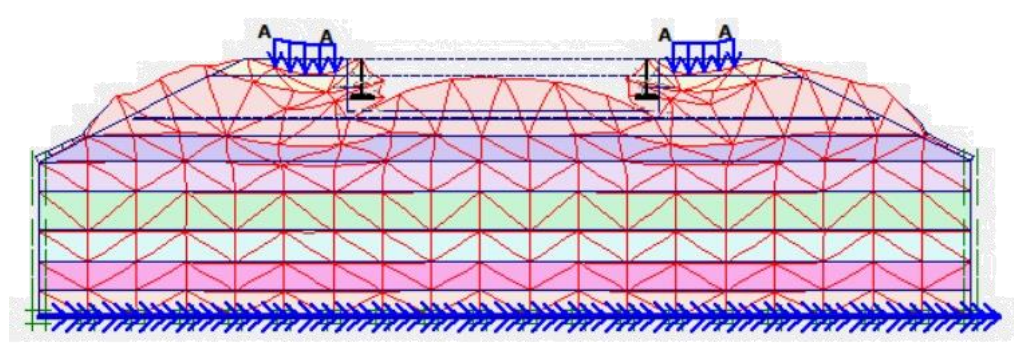

Gambar 5. Deformasi pada mesh element untuk dinding penahan tanah dengan soldier piles

Data dalam Tabel 3 menunjukkan bahwa perhitungan dengan pembebanan gempa mengurangi angka keamanan, sesuai dengan hasil yang ditunjukkan pada dinding penahan tanah dengan reinforced earth wall pada Tabel 1 dan hasil dari [1]. Angka keamanan metode soldier piles lebih besar 3-4 kali lipat dari angka keamanan dinding penahan tanah menggunakan reinforced earth wall.

Tabel 3. Angka keamanan Soldier Piles sepanjang $19 \mathrm{~m}$.

\begin{tabular}{llc}
\hline No. & Keterangan & Angka Keamanan \\
\hline 1. & Kondisi tanpa gempa & 6,408 \\
2. & Kondisi dengan gempa & 5,493 \\
\hline
\end{tabular}

Analisis tentang stabilitas eksternal meliputi angka keamanan terhadap geser dan guling dilakukan berdasarkan perhitungan tegangan tanah horizontal seperti yang ditunjukkan data dalam Gambar 6 dan Gambar 7. Nilai parameter berat volume tanah $\left(\gamma_{t}\right)$, sudut geser dalam $(\varphi)$, kohesi $(c)$ didasarkan pada nilai NSPT.

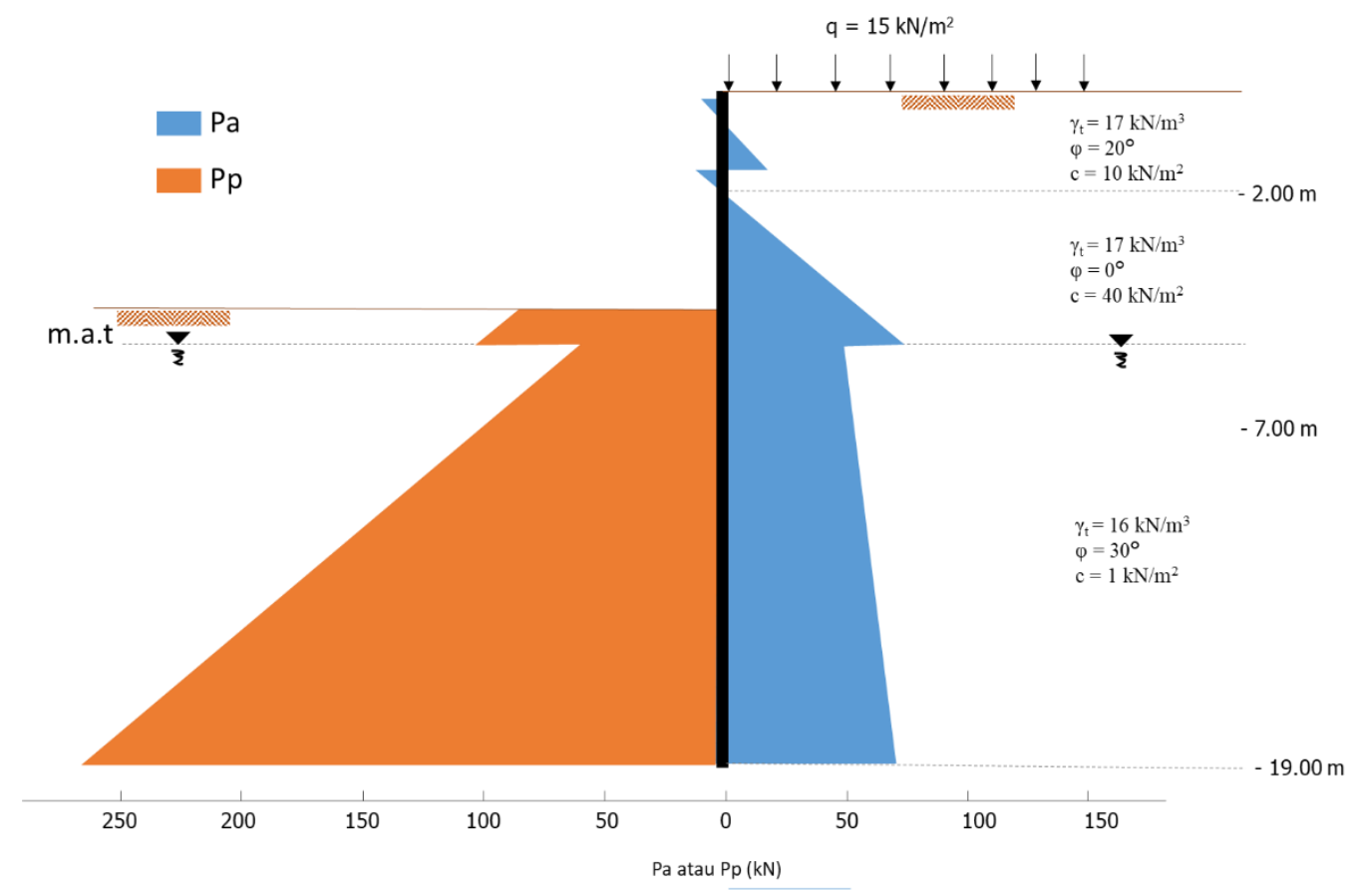

Gambar 6. Diagram tekanan tanah horizontal pada dinding penahan tanah menggunakan soldier piles 


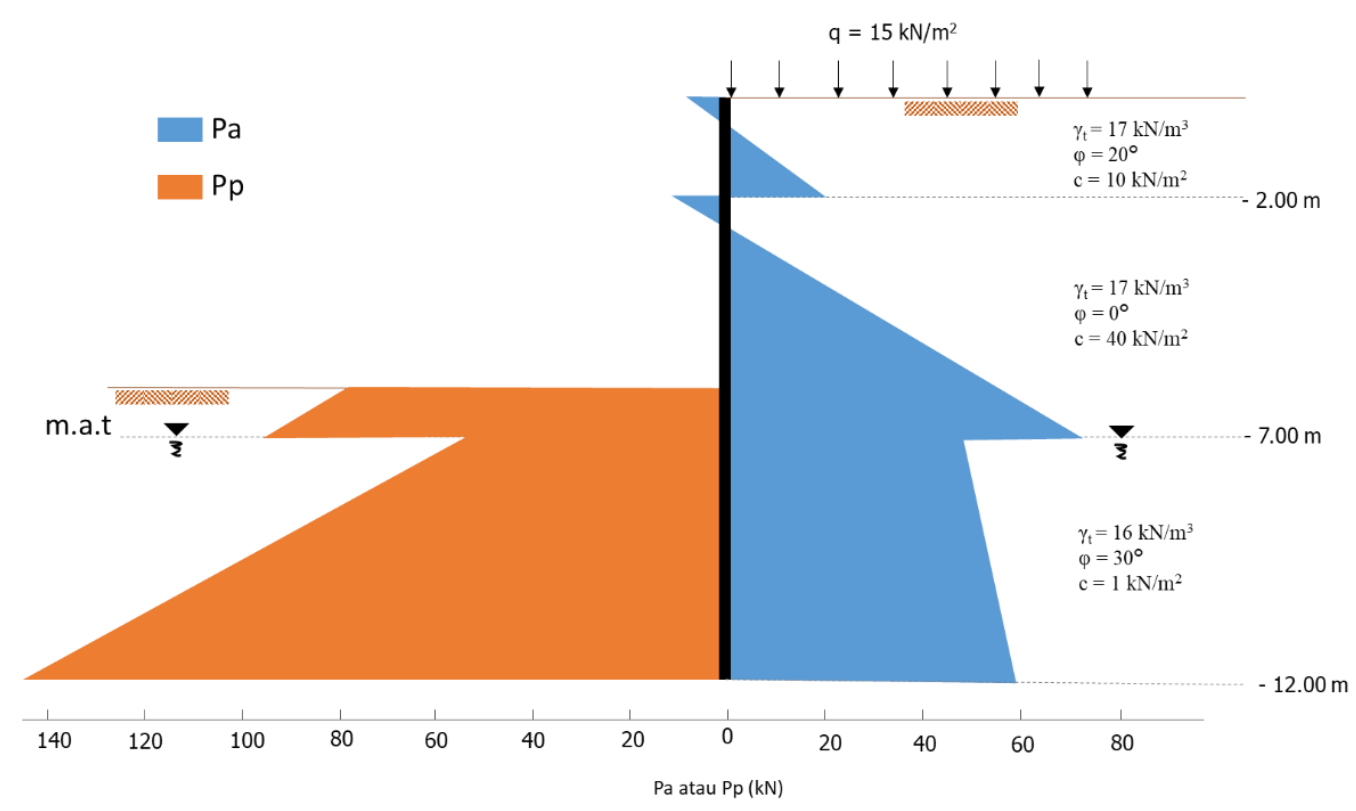

Gambar 7. Diagram tekanan tanah horizontal pada dinding penahan tanah menggunakan reinforced earth wall

Tabel 4 menunjukkan angka keamanan stabilitas eksternal dinding penahan tanah menggunakan soldier pile maupun reinforced earth wall dengan perkuatan geogrid berdasarkan rumus (1), (2), dan (3).

Tabel 4. Angka keamanan stabilitas eksternal dinding penahan tanah.

\begin{tabular}{lcc}
\hline & Soldier Piles & Reinforced Earth Wall \\
\hline SFgeser & 2,13 & 1,97 \\
SFguling & 1,50 & 4,31 \\
\hline
\end{tabular}

\section{Kesimpulan}

Berdasarkan hasil analisis dapat diambil kesimpulan sebagai berikut: (1) Stabilitas internal maupun stabilitas eksternal dinding penahan tanah dengan soldier piles maupun reinforced earth wall menunjukkan SF>1,5 yang berarti lereng relatif stabil, (2) Angka keamanan dinding penahan tanah dengan soldier piles lebih besar daripada reinforced earth wall, dengan dimensi tiang yang tertanam sedalam 13 meter, (3) Stabilitas terhadap guling pada reinforced earth wall lebih besar dari soldier piles, karena momen perlawanan yang dihasilkan lebih besar daripada momen pendorong, (4) Pemilihan penggunaan metode dinding penahan tanah pada area STA $2+200-2+400$ sebaiknya melalui pertimbangan pada kebutuhan material, waktu pelaksanaan, dan biaya yang dibutuhkan sehingga dapat memberi efisiensi dan efektifitas pada pekerjaan tersebut.

\section{Referensi}

[1] R. Rekzyanti, S. Balamba, and L. Manaroinsong, "Analisa Kestabilan Lereng Akibat Gempa (Studi Kasus : IAIN Manado),” TEKNO Vol.14/No.66/Desember 2016 ISSN 0215-9617, vol. 14, no. 66, pp. 2333, 2016.

[2] F. A. Putri, "Pengaruh Nilai Kohesi Tanah Terhadap Stabilitas Retaining Wall pada Basement Gedung Bertingkat," Universitas Lampung, 2016.

[3] B. M. Das, Principles of Foundation Engineering. 2016.

[4] Y. Hastuti, R. M. Wahyuni, and R. Dewi, "Perkuatan Lereng Dengan Geogrid Dan Sheet Pile Pada Jalan Kikim Besar (KM. 256) Kota Lahat,” vol. 4247, no. April, pp. 1-6, 2016.

[5] J. Bowles, Physical and Geotechnical Properties of Soil. 1984. 